\title{
Impact of the regulatory reserve and capacity demand on the process of justification of the generating sources in respect of the UES Russia management development
}

\author{
Chukreev Yu. Ya, Chukreev M. Yu.* \\ Institute for Socio-Economic \& Energy Problems of the North Federal Research Center of the Komi Science Centre \\ of the Ural Branch of the Russian Academy of Sciences, Syktyvkar, Russia
}

\begin{abstract}
An analysis is made of the regulatory documents used to justify the capacity demand and one of its components - the normative capacity reserve. The methodological principles for considering energy availability at hydroelectric power stations from the standpoint of justification of reserve funds are justified. For the price zones of the UES Russia, retrospective information on the forecast values of maximum loads and power generation at hydroelectric power stations has been compared with their actual values. The article gives the practical results of influence of the identified regulatory documents inconsistencies and deviations of the maximum load forecasts and hydroelectric power generation from the actual power demand values and the justification of the generating sources to cover it under a competitive power selection procedure.
\end{abstract}

\section{Background of the problem}

The justification of the generating sources in development management the of the electric power industry and the UES Russia in particular depends, in one way or another, on the values of the planned power consumption and the maximum loads. The latter are known to be formed in the planned for perspective power and electricity balances (fig. 1). This information is in accordance with the decision of the Government of the Russian Federation ${ }^{471}$ since 2010 is annually formed in the work «Scheme and program of development of the UES of the country for the 7-years period» (SPD), carried out by JSC «SO UES» and Federal Grid Company.

In a power balance, as in any balance sheet, there are revenue and expenditure sides. The expenditure side of the balance is determined by the demand for capacity and consists of three components: projected maximum load, export/import capacity and the capacity reserve. The incoming part of the balance shall be determined by the installed capacity of the generators of the power plants minus various power constraints on the maximum load, the power inputs after the passing thereof, the power output not released (latched) power. In a balanced variant, the coverage of the demand of the incoming part shall correspond to the demand for the power consumption in the expenditure part of the power capacity balance. The current state of the industry is characterized by the significant excess capacity and corresponds to the picture in Fig. 1. In fact, this explains the strong focus on determination of the capacity demand. Its value determines the justification of the generating sources involved in meeting the demand in managing development of the Russian UES for a period of up to seven years in the market procedure of a competitive power selection (CPS).

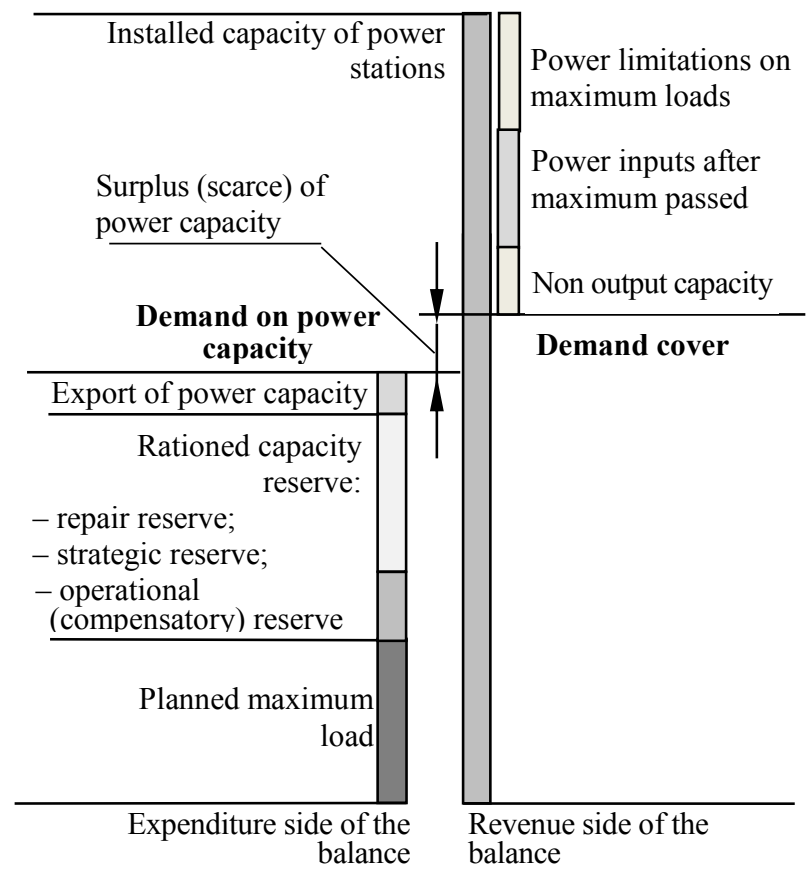

Fig. 1. Structure of the projected power balance.

The planned maximum load for each calendar year of the seven-year period is calculated based on the forecast of capacity consumption in the territories of the constituent
${ }^{1}$ The Rules for Development and Approval of schemes and
programs for the Future Development of Electric Power Industry,

* Corresponding author: iespn@.ksc.komisc.; iespn@mail.komisc.ru approved by the Decision of the Government of the RF dated on 17.10.2009 № 823 . 
entities of the Russian Federation for the conditions of the average multi-year ambient air temperatures of the territories under consideration, for the month of December. Standard (full) capacity reserve includes operational (recently called compensatory), repair and strategic capacity reserves. The operational reserve capacity is a subject to many factors, including the incidental factors. Its justification is based on the task of estimating balance reliability indicators (BRI) for the calculation scheme of the UES of the Russian Federation with its territorial zones of reliability [1-4]. These were in the pre-perestroika period United Electric Power Systems (UPS). Recently, there has been a tendency to apply more detailed calculation schemes of the Russian UES by splitting UES into the territorial zones (from 42 to 56 zones). In our view, due to the complexity of the information content, fragmentation is appropriate in order to solve the task of assessing the BRI development options of the UES Russia. The studies show that such fragmentation is inefficient in terms of both reliability and computational efficiency to justify the operational component of the normative power capacity reserve.

During the pre-perestroika period, the percentage values of the normative power capacity reserve from the maximum load in UPS of UES Russia were given in the methodological recommendations (MR) on the power systems development projecting. The latest edition was made in the mid-1990s [5]. The Ministry of Energy of the Russian Federation approved them only in 2003. The current state of the electric power industry has undergone significant changes that require updating. It was launched in 2011, almost immediately after the start of the annual work of SPD of the UES. JSC «SO UES» ordered by JSC «INSTITUTE OF ENERGOSET'PROEKT» with the involvement of the research institutions, the new edition of the MR was carried out taking into account the changed conditions ${ }^{2}$. On the initiative of the contracting authority of the work in this revision, the values of the normative reserve of capacity were substantially inflated from 17 to $20.5 \%$ for the UES Russia and from 12 to $22 \%$ for the UPS of Siberia. The increase was primarily in the component of the capacity reserve for providing the routine equipment repairs. For example, in relation to the 2003 edition of the MR, there has been a twofold increase in the repair component in the European part of the UES (from $4-5 \%$ to $9-10 \%$ ), in the UPS of Siberia even to the three-fold component (from $4 \%$ to $12 \%$ ). The rationale for this increase is known and is dealing with the need to attract investors to meet the obligations of the generating companies to bring in new capacity under condition of the guaranteed payment. The increase in the statutory reserve of capacity and therefore in the demand for capacity certainly contributes to this.

The explanation of this fact is quite simple. With the launch of the market in 2006, the capacity of the normative length and periodicity of repairs, as well as the prospective five-year plans for the repair of the major plant equipment at

\footnotetext{
${ }^{2}$ Methodological recommendations on the project development of power systems / OJSC «Institute « Energoset'proekt», 2012 (approved by NP «NTS UES», section «Technical regulation in electric power industry» in July 2012.

3 Regulation on the procedure for determining the demand for capacity for long-term competitive power selection in the
}

the power electric stations have lost their regulatory role. The regime-and-balance situation (the sharp decline of electricity consumption), financial possibilities and rules for the wholesale market for electric energy (capacity) allowed energy companies to carry out repairs also in the autumnwinter period. Statistical information on their conduct has changed. While planning of the sectoral development, the December day component of scheduled repairs was included in the value of the standard capacity reserve. Ministry of Energy of the Russian Federation did not approve the MR 2012 in that version.

Early in the year of 2018, Ministry of Energy of the Russian Federation again initiated the work on the procedure for determining the normative reserve of the power capacity. Melentiev Energy Systems Institute SB of the RAS and ISE\&EPS FRC Komi SC UB of the RAS participated in the implementation of this work initiated by JSC « NP Market Council ». In the beginning of 2019 the ISE\&EPS FRC Komi SC UB of the RAS was suspended for the unknown reasons. Although the completion of the work was foreseen at the end of 2018, the work carried out by Melentiev Energy Systems Institute $\mathrm{SB}$ of the RAS has not been completed until the present day.

\section{Analysis of the legislation and regulations to justificate the capacity demand}

The challenge of justifying the generating sources contributing in covering the power demand (Fig. 1) should now be studied in a completely different way, more in relation to the dismantling than to the introduction of the new generating equipment. In the context of the market relations, justification for introduction of the new generating equipment in the UES Russia is carried out in order to solve the tasks of the power contracts, justification of capacity participating in the demand cover, the status of the forced generation and dismantling of obsolete and obsolete equipment as a result of the competitive bidding in a closed competitive auction.

Implementation of the changed conditions required development in 2010 «Regulations on the procedure for determining the amount of demand for power...» approved by the Ministry of Energy of Russia ${ }^{3}$ (thereinafter Order № 431). In accordance with para. 3.1 of this Regulation, the planning coefficient of power reserve of capacity is calculated by JSC «SO UES» for the free power transfer zone(s) (groups of zones), as the sum of the value that equals 1.17 , coefficient of the power underutilization factor and the coefficient taking into account electrical energy export. The demand for the power capacity at that is determined by multiplying this coefficient by the predicted combined maximum consumption, taking into account the effect of the temperature factor. This paragraph is in the substantial contradiction with the MR 2003.

wholesale market of electric energy (capacity) and the procedure for determining the planning coefficients for reserving capacity in zones (groups of zones) free flow of electrical energy (power capacity), approved by the Order of the Ministry of Energy of Russia of 07.09.2010.№ 431 (edition on 17.08.2017). 
The coefficient 1.17 corresponds to $17 \%$ of the full reserve of capacity from the maximum load given in the MR 2003 for the European part of the UES Russia. For UPS of Siberia this percentage in the regulation is only $12 \%$. In the Order №431, the coefficient of 1.17 has been extended to the UES of Russia as a whole for unexplained reasons. The power capacity underutilization coefficient, which is a part of the planned reserve factor, in accordance with the Order №431, para.3.2, takes into account the actual power reduction resulting from the unscheduled repairs of the generating equipment. It is determined by the ratio of the average monthly power capacity reduction from the values specified in the notifications submitted under the Rules of the Wholesale Market for the selection of the equipment composition in the winter months of two years prior to the date of the long-term CPS, to the projected maximum consumption volume. The occasional underutilization of capacity caused by the same causes, and precisely for the month of December, is taken into account and is, moreover, the main reason for the operational reserve component of the standard (full) capacity reserve (coefficient 1.17) received in the MR 2003. There is a double counting of the same random parameter.

The temperature factor is taken into account in the Order №431 by multiplying the projected maximum load by the temperature coefficient over the territorial areas of the UES Russia. This leads to an increase in demand by more than $4 \%$. The same factor, which is generally random, is taken into account in the balance sheet support models by introducing a predictive error parameter [1-3]. Described in the MR 2003 percentage of the full power capacity reserve $(17 \%$ of the maximum load) are received taking in account that factor. If not considered, this percentage would fall to $12-14 \%$ [2]. It can be stated that here again there is a double counting of the same randomly conditioned parameter. Unfortunately, the specialists who prepared the Order №431 did not involve in its preparation and expertise scientists of the academic and university science, as well as the sectoral Institutions, who are in charge of ensuring the balance reliability of the EPS.

Another important point related to the adopted values of the planned calculated reserve ratio is given in the Paragraph 107 of the Rules of the Wholesale Market ${ }^{4}$ (hereinafter GD RF №1172). It increased its value for the second price zone of the wholesale market by $8.55 \%$. The rationale for this increase remains a mystery for many energy professionals. It is understood that under the conditions of available excess capacity, the most efficient of existing plant assemblies should be selected when justifying generating sources. In the economic aspect of hydropower stations, if there is excess capacity in the power system are more attractive than the thermal stations due to the lower operating costs (no fuel component). At the same time, their modes of operation depend on weather conditions (low-water years) and these aspects (economy and energy supply) should be taken into account when justifying reserve funds under the present conditions of excess capacity.

\footnotetext{
4 The Government Decree of the RF № 1172 dated on 27.12.2010 (edit. on 19.01.2018) «On the Approval of the Rules of the Wholesale Market of Electric Energy and Power capacity and on the Amendment of some acts of the Government of the Russian
}

\section{Methodological principles for taking into account restrictions on the production of electricity at hydroelectric power station when justifying power capacity reserves and their practical applications}

It should be noted that the method of justifying the normative reserve of capacity to compensate for the withdrawal of the generating equipment to the unplanned (emergency) repairs (operational reserve as revised by the MR 2003) remains unchanged. In the present circumstances, unfortunately, there are no scientifically based provisions for the application of the criteria for decision-making on the level of reliability. This could be based either on the western European standards ( $L O L H=3-8$ hours/day), or North American ( $L O L E=0.1$ time a year), on the national standards for the territorial zones $[1,4]\left(J_{д}=0,004\right)$.

For all of the listed balance reliability indicators, the methodological basis for obtaining them is roughly the same and the information component is quite different, especially with regard to the treatment of the electrical consumption patterns [1]. The European standard for the balance reliability estimates hourly power consumption schedules for all 8,760 hours of the year, while the North American standard only takes into account the maximum hour of the day a year (365 values). The domestic national standard for the balance reliability targets only one average hourly daily schedule in December, assuming that it is valid for all working days of the year. The comparison of these indicators, in terms of their impact on the justification of funds, is a rather complex undertaking. In the research work [1] for the certain conditions, studies have been carried out which have shown an acceptable convergence of results in justifying the value of the operational component of the normative reserve of capacity.

Regardless of the management principles of the power industry (centralized, market), the task of the estimation BRI by using combinatorics or statistical modelling methods is based on two interrelated steps:

- formation of the load levels and random generation capacity conditions caused by the unplanned findings in emergency repair of the power plant equipment;

- assessment of the formed states of provision of the load in the territorial zones.

It should be understood that the task of the BRI estimation is an integral part of solving the problem of justifying the operational component of the normative capacity reserve. So far, in the BRI EPS assessment models the types of the generating equipment involved in meeting the consumer demand have not been specified. Moreover, this was justified because in estimating the BRI out of the multitude of randomly formed states of generating capacity and load is less than a percent. It should be noted that only in these deficit states the generating capacity is fully used. In the states without a deficit, which are more than $99 \%$, the generating power exceeds the load. These states do not affect the PBN,

Federation on the Organization of the Wholesale Market of Electrical Energy and Power capacity». 
so from the point of view of providing a power balance, the generation can be redistributed as much as possible between different types of stations (HPP, TPP, NPP, RES).

The contribution of a hydroelectric power station in covering the load in the absence of a deficit state can be taken into account only when the power reduction functions caused by the output of the equipment in the unscheduled (emergency) repair can be formed separately for thermal, including nuclear power plants and for hydro units of seasonal (annual) flow control. The methodological approaches for estimating each generation state of a HPP and TPP must also be changed. Considering that the power capacity redistribution between the HPP and the TPP with the NPP can only be carried out in the absence of a deficit state and does not in any way affect the BRI, it is possible to apply the maximum load rule on these states at thermal and nuclear power stations. In this case, the BRI estimation algorithm is designed so that the load at the HPP from one randomly formed absence of the deficit state to another might change [6]. The process of changing is dynamic. The final result of simulating a large number of random states is to achieve, if possible, planned indicators of electricity generation at the HPP (from the perspective of non-renewable energy savings). The simulation is done for all time intervals (day, season, year) for which information is available on the planned indicators of power generation at a hydroelectric power plants.

The application of a separate random state simulations in the estimation of balance reliability indicators for HPP, TPP with NPP makes it possible to determine the generating capacities required to provide the load separately for these types of stations. This opens up the possibility of determining the required additions to the value of the normative reserve of capacity caused by the insufficient energy supply of the hydroelectric power stations in the low-water years. This requires two calculations to determine the operational reserve of capacity, which is an integral part of the statutory reserve of capacity, for the projected hydroelectric power generation and for a low-water year. In both calculations, the operational reserve of capacity remains unchanged, but due to the change in the power supply of the hydroelectric power station, the power generating capacity of the participating payers will be redistributed between the HPP and TPP with NPP. The difference in redeployment will be a premium to the operational and therefore normative capacity reserve due to the reduction in the energy supply of the hydroelectric power station in the low-water years. The most difficult in this approach is the uncertainty of information on the energy supply at a HPP.

Obtaining practical results on energy accounting of a HPP involves modernizing the existing software («Orion-M» $[1])$, including additional content [6]. The research studies conducted are based on actual information obtained in the course of the research work ${ }^{5}$. Information on the energy supply of HPP Siberia UPS is taken from the work made by SPD. Application of the developed methodology showed the existence of a strict correlation between the percentage of the reduction in electricity production at the UPS Siberia hydroelectric power plants in the low-water years

\footnotetext{
5 Report on the scientific research work "Justification of the normative values of the components of the full reserve capacity in the UPS and UES Russia in the planning of their development. /
}

$(95673 / 107377100=10.9 \%)$, the share of the projected value of their electricity production in relation to its total volume $(107377 / 209729=0.512)$ and per cent additions to operational reserve capacity. The product of the first and second components is almost always the same as the third one. Then the addition to the normative reserve of capacity of a value of $8.55 \%$ of the combined maximum load can be obtained when the difference of electricity production at the Siberia UPS hydroelectric power plants for the calculated and low water years is $16.7 \%$.

A natural question arises - what is the significance of the production of electricity at the hydroelectric power station of UES Siberia when justifying the normative reserve of power to be taken as calculated? This is a sufficiently important and unexplored issue in the justification of the normative reserve capacity. The study was not required under the centralized management of the industry. At that time, it was not the task of identifying the most efficient capacities due to their obvious lack of capacity (the frequency in the system was almost always below the regulatory value). In the present situation of excess capacity, the issue of taking into account the energy supply of hydroelectric power is becoming sufficiently topical.

Two options are possible to accept the calculated value of electricity production at the Siberia hydroelectric power plants. The first one is acceptance of the projected with a high-probability to be implemented (formulation from the Electricity Balance in the work of SPD) electricity production volumes. The second option is the acceptance of an average value based on the analysis of retrospective information on the actual electricity production. In order to shed some light on the situation, an analysis of the retrospective information on the actual and projected electricity production at the hydroelectric power plants of Siberia is provided below.

\section{Analysis of the forecast of power consumption and electric power production at hydroelectric power stations}

The report of SPD 2019-2025, made in 2019, is the 10th since their formation in 2010. This allows based on the retrospective information to make some conclusions and to compare the planned maximum loads and the generation of electricity on a hydroelectric power plants with their actual values. The comparison is made for the period of 2016-2019, for which all the required information is available.

Forecasting of the maximum loads. The value of the planned maximum load is the basis of the capacity demand of the power consumption part of the power balance (Fig. 1). This implies that errors in the forecast have a significant impact on the justification of the generation capacity of the contributing capacity to the power budget. Taking into account these circumstances in JSC «SO UES» the unified system of forecast of production and consumption of electricity and power capacity up to 7 years has been created. The power consumption forecast is prepared for the hour of maximum in December for the average daily temperature of

Syktyvkar, 2016 - 66 p. (Contract ISE\&EPS FRC Komi SC UB of the RAS with JSC «SO UES», № 926 dated on 22 September 2016). 
the maximum power consumption averaged over the 10 years preceding the autumn-winter period. It takes into account the actual capacity balances of previous periods, plans for technological accessions of facilities, and macroeconomic indicators in accordance with socio-economic development scenarios.

It is obvious that the amount of the planned maximum load is influenced by the period of anticipation (from 1 to 7 years). The analysis shows that this period is steadily increasing when conducting the procedure for justifying the generating capacity of participating in meeting the demand for capacity (CPS procedure). So until 2016, the following procedure was based on the two-year forecasts, for 2016 and 2017 with three-year forecasts. For 2024 and 2025 forecasting has reached the limit of 7 years for the SPD.

Let us provide a brief analysis of the comparison of the planned maximum load with their actual parameters for 20162019 for a period of one to seven years. Consideration of the time before 2016 is not possible due to lack of information in works of SPD, the first of which gives a forecast for 7 years only for 2016. It is not possible to review later than 2019 due to lack of information on actual parameters of the capacity consumption.

Figure 2. provides information for the period of 2016 2019 on the percentage deviations of the projected maximum load parameters (from the work of the SPD) from the actual values for the price zones of the European part of the UES of Russia and Siberia. In Fig. 2 two dotted lines: 2 - average deviations from the actual parameters for the four-year period under review, thinner lines 3 - their max and min bypassing lines. It should be noted, however, that for both price zones from 2013 to 2019 there is a little increase in the actual load maximums by their average value (in Fig. 2 dependence 1 the line in bold). significant increase in the forecasted parameters of the maximum load over the actual values for the 4-year period under analysis can be explained by the first works of the SPD 2010-2016 - 2012-2018 trends in the increase of consumption from year to year, which does no credit to the power balance developers. It should be noted that in subsequent works of the SPD this trend is reduced to the reasonable limits. However, a systematic error in forecasting for the first year (from 2 to $3 \%$, fig. 2) remains. Based on the presented above analysis, when carrying out the justification procedure of the generating capacity, or CPS, the deviations of the 7-year period of anticipation of the maximum load parameters from their actual values should be:

- for the first price zone from 6 to $8 \%$, and taking into account the systematic deviation for a one-year $-5 \%$;

- for the second price zone from 11 to $13 \%$, taking into account the systematic deviation for a one-year $-10 \%$.

Forecast of the electric power production at the hydroelectric power stations at UPS Siberia. While planning power balances in the SPD operations, the amount of electricity produced at the HPP for the territorial zones in the form of UPS is given for the most water-friendly scenarios. For the Siberia and the Far East, where the share of electricity production at the hydroelectric power plants is significant (from 35\% and above), since 2012 the electricity balance is given for a low-water year. Fig. 3 by analogy with fig. 2 shows the percentage variation of the forecasted electricity production parameters from the actual values for the 7-year period for the Siberia hydropower plants and the change in actual electricity production for the period of 2013-2018 from the average values over the years (the solid line in bold -1 ).

Significant average (10\% in Fig. 3, dependency 2$)$ and maximum ( $15 \%$, dependency 4$)$ deviations of the projected actual values of production at the hydro energy power plants

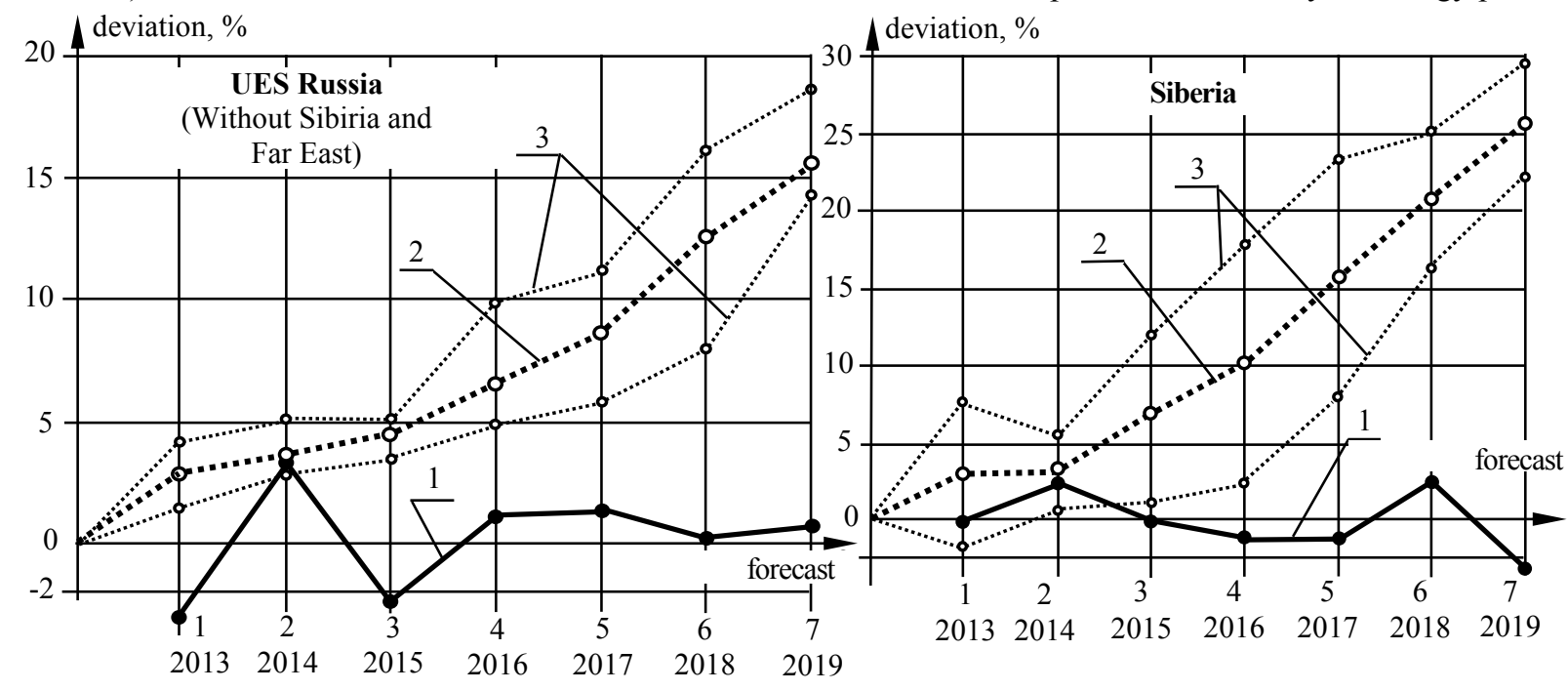

Fig. 2. Deviation of the forecast loads (with a high probability of implementation) from the actual meanings for the UES Russia without UPS Far East and Siberia (from 10 issues of the SPD from 2010 - 2016 until 2019 - 2025).

It can be seen that when the forecast period for both price zones increases the deviations also increase significantly. For the one-year forecast, the average deviations for both price zones are about $3 \%$, for the seven-year period more than $15,5 \%$ for the first price zone and $25 \%$ for the second price zone. Why such large deviations in forecasting of the maximum consumption for one year cannot be explained. The from the actual values for all forecast periods. For a lowwater year, these forecasts are, as expected, slightly lower than the actual electricity production (4-year averages of about $7 \%$, maximum possible between 11 and $15 \%$, dependencies 3 and 4 respectively). At the same time, the planned for the coming year electricity generation for the most likely and the low-water year coincide. Explanations for 


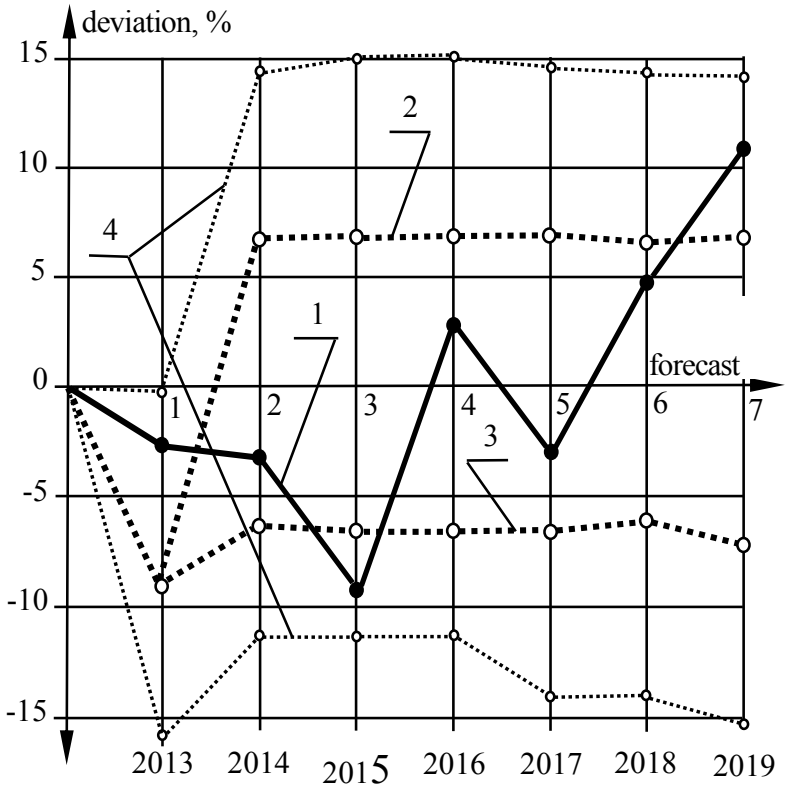

Fig. 3. Deviations of the projected parameters of the electricity production at the hydroelectric power stations Siberia from the actual values for the period of seven years.

this phenomenon, as well as the sharp increase in the period under review from 2016 to 2019 of the average values of the generation of electricity on a hydroelectric power plants for the most likely scenario and the sharp decrease for a lowwater year for a forecast period of 2 years or more is not available (dotted lines 2 and 3 ).

Given in fig. 3 dependence of deviations of the actual values of the electricity production on average for the period of 2013-2019 (line 1) for HPP in Siberia has a sufficiently strong fluctuation. The maximum reduction in electricity production was $9.2 \%$ (2015). If we consider deviations of the average projected electricity production parameters for a lowwater year from their actual values for the warning period from 2 to 7 years, they range from $7 \%$ (dependency 3 ). However, the maximum deviations considered in one out of four studied retrospective period range from $12 \%$ to $15 \%$ (thin dotted line 4 in Figure 3).

Analysis of the retrospective information shows that $16,7 \%$ of the difference in the electricity production at the hydroelectric power plants at the Siberia UPS can only be achieved by considering the maximum deviations of the projected electricity production parameters for the probable scenario and for the low-water year (dotted lines 4 in figure 3). Considering the mean values (dependencies 2 and 3 ) can only be achieved by $14 \%$. When considering the projected generation of electricity for the most likely and the low-water years, an interesting picture emerges. The greater the gap in the forecast of the electricity production at the hydroelectric power plants, the greater the additions to the value of the regulatory reserve. At that, the retrospective information on the ratio of the actual electricity production at a hydroelectric power plants with its projected values is not at all taken into account. Thus, the most important parameter of the actual electricity production at the Siberia hydroelectric power plants falls out of consideration. In our view, when justifying a reserve of capacity, it is necessary to consider the risks of underproduction of the electric power at hydroelectric power plants during the low-water years, taking into account the average values of its actual production, taking into account its evolution for the projection period, based on, inter alia, on the analysis of the retrospective information on those parameters. In such case, according to the characteristics given in Fig. 3, the reduction of the electric power production at the Siberia hydroelectric power plants during the low-water years should not exceed $7.0 \%$ on average (in Fig. 3, dependence 3), and on the basis of the actual deviations $9.2 \%$ (dependence 1, made for 2015). This corresponds to the addition to the normative capacity reserve not 8.55 per cent, adopted in the GD RF №1172, but from 3.58 to 4,72 per cent.

\section{Conclusion}

The perceived contradictions in defining the projected amount of capacity demand effect on the generating capacity justification that participates in its covering during the competitive power selection procedure. In the beginning of 2020 , the CPS procedure was conducted for $2025^{6}$. Table 1 shows the parameters used for the survey and adjusted to take account of the contradictions in the article on capacity demand in the price zones of the UES Russia. The table shows that the amount of demand for power to justify the generating sources of its covering in the adjusted variant is significantly decreasing - by more than $8,5 \%$ in the first and slightly less than $15 \%$ in the second price zones.

According to the paragraph 107 of the Rules of the Wholesale Market (RF GD № 1172), the price for the power

Table 1. The initial and adjusted information for the competitive power capacity selection procedure for 2025 .

\begin{tabular}{|c|c|c|c|c|c|c|c|}
\hline \multirow{2}{*}{$\begin{array}{c}\text { Price } \\
\text { zone } \\
\text { number }\end{array}$} & \multicolumn{3}{|c|}{ Projected maximum capacity consumption, $\mathrm{MWt}$} & \multicolumn{2}{|c|}{ Planned coefficient of reservation, $\%$} & \multirow{2}{*}{$\begin{array}{l}\text { Development of } \\
\text { objects of the } \\
\text { retail generation }\end{array}$} & \multirow{2}{*}{$\begin{array}{c}\text { Demand on the } \\
\text { power capacity } \\
\text { MWt } / \%\end{array}$} \\
\hline & $\begin{array}{l}\text { From the work SPD } \\
\text { UES for 2019-2025. }\end{array}$ & $\begin{array}{c}\text { With } \\
\text { combination }\end{array}$ & $\begin{array}{l}\text { Taking into account } \\
\text { the temperature factor }\end{array}$ & estimated & applied & & \\
\hline \multicolumn{8}{|c|}{ Initial information } \\
\hline 1 & 132441 & 127547 & 133011 & 18.4 & 18.4 & 7143 & $150342 / 100$ \\
\hline 2 & 34704 & 33845 & 35283 & 18.0 & 26.55 & 1311 & $43339 / 100$ \\
\hline Total & 167145 & 161392 & 168294 & - & - & 8454 & $193681 / 100$ \\
\hline \multicolumn{8}{|c|}{ Corrected information } \\
\hline 1 & 126135 & 121474 & 121474 & 19.05 & 19.05 & 7143 & $137472 / 91.44$ \\
\hline 2 & 31548 & 30767 & 30767 & 13.41 & 24.41 & 1311 & $36966 / 85.29$ \\
\hline Total & 154243 & 148925 & 148925 & - & - & 8454 & $174438 / 90.06$ \\
\hline
\end{tabular}

\footnotetext{
${ }^{6}$ Website of the JSC "SO UES" "Competitive capacity selection", monitor.so-ups.ru
} 
capacity is determined based on a two-point linear demand function. The important thing is that according to the Government Decree of the Russian Federation № 1172, the prices for the points of demand for the power capacity are strictly determined by the price set by the Government of the Russian Federation in 2017. Taking into account the indexation in the first and second price zones made for 2025 , they were 209051.27 and 292415.27 rub. respectively/MWt for the first point of demand. Analysis of the procedures conducted by CPS shows that the final price is no more than $10 \%$ different from the initial price of the first demand point. For example, for 2025 the price for the power capacity after the conducted procedure of CPS was 193157,87 for the first price zone, for the second - 303191,67 rubles/MWt. This allows to determine the economic component of the reduction in the cost of the purchasing power by consumers, taking into account the contradictions identified above. For the first price zone it makes the amount of $(150342-137472) \times 193157.87=$ 2485930.6 thousand $\mathrm{rub} / \mathrm{month}$, for the second one $(43339-36966) \times 303191.67=1932240.50 \quad$ thousand rub./month. The annual reduction of power charges by large consumers of both price zones will be quite large - more than 53 billion rubles.

\section{References}

1. Chukreev Yu.Ya., Chukreev M.Yu. Modeli otsenki pokazateleyi balansovoyi nadezhnosty pri upravlenii razvitiem elektroenergeticheskikh system. Syktyvkar: Komi SC UrO RAN, 2014, 207 p.

2. Chukreev Yu.Ya. Modeli obespecheniya nadyozhnosti elektroenergeticheskikh system. Syktyvkar: Komi SC UrO RAN, 1995,176 p.

3. Kovalev G.F., Lebedeva L.M. Nadyezhnost' system elektroenergetiki. Novosibirsk: Nauka, 2015, 224 p.

4. Billinton, R. Reliability Evaluation of Power Systems. Second Edition / R. Billinton, R.N. Allan. New York and London: Plenum Press, 1996. 509 p.

5. Metodicheskie rekommendatsii po proektirovaniyu razvitiya energosystem. (Utverzhdeno Prikazom Minenergo Rossii ot 30 June 2003, № 281). M.: Minenergo RF, CO 153-34.20.118-2003.

6. Chukreev Yu.Ya., Chukreev M.Yu. Metodicheskiye principy uchyeta gydroelektrostantsiy $\mathrm{V}$ zadache obespecheniya balansovoy nadyezhnosty EES Rossii // Metodicheskiye voprosy issledovaniya nadezhnosti bol'shikh system energetiki: Issued. 70. Metodicheskiye i prakticheskiye problemy nadyezhnosty system energetiki. V 2-kh knigakh. / Kniga 1 / otv. red. N.I. Voropayi. Irkutsk: Melentiev Energy Systems Institute SB of the RAS, 2019. - 54-63 p.

1. Chukreev Yu.Ya., Chukreev M.Yu. Models for assessing balance reliability indicators in managing the development of electric power systems. Syktyvkar: Komi SC UB RAS, 2014, 207 p.

2. Chukreyev Yu.Ya. Models of reliability of electric power systems. Syktyvkar: Komi SC UB RAS, 1995. 176 p.
3. Kovalev G.F., Lebedeva L.M. Reliability of power systems. Novosibirsk: Nauka, 2015, 224 p.

4. Billinton, R. Reliability Evaluation of Power Systems. Second Edition / R. Billinton, R.N. Allan. New York and London: Plenum Press. 1996. 509 p.

5. Guidelines for the design of energv svstems. Approved by order of RF Ministrv of energv .June 30, 2003, № 281. M.: Ministry of energy Russian Federation, 2003.

6. Chukreev Yu.Ya., Chukreev M.Yu. Methodological principles of accounting hydro power plants in the problem of ensuring the balance reliability of UES of Russia // Methodological issues of research the reliability large energy systems: Issued. 70. Methodical and practical problems reliability of power systems. In 2 books. / Book 1 / executive editor N.I. Voropayi. Irkutsk: Melentiev Energy Systems Institute SB of the RAS, 2019. $-54-63 \mathrm{p}$. 